In multivariable modeling, after adjusting for age, sex, and education, large joints had greater effects (tender $0.074(0.065-0.084)$, swollen $0.027(0.014-0.04)$ ) on $\mathrm{HAQ}$ than hand joints (tender $0.013(0.009-0.017)$, swollen $0.008(0.003-0.013)$ ). Conclusions: Both Lansbury and standard joint count trajectories correlate similarily with HAQ in ERA. The weighting of large joints in LAI was insufficient to reflect the full impact of large joint involvement in ERA probably because HAQ questions emphasize large joint activities. The effects of large joint swelling may be under recognized due to difficulty in measuring hip, shoulder or elbow swelling. Overall, tender joints had a greater impact on function than swollen joints and large tender joints had the most impact on function.

Disclosure of Interest: S. H. L. Lim: None declared, O. Schieir: None declared, S. Bartlett Consultant for: Pfizer UCB, G. Boire: None declared, B. Haraoui Grant/research support from: AbbVie, Amgen, BMS, Janssen, Pfizer, Roche and UCB, Consultant for: AbbVie, Amgen, BMS, Celgene, Eli Lilly Janssen, Merck, Pfizer, Roche and UCB, Speakers bureau: Amgen,BMS Janssen, Pfizer and UCB, E. Keystone Grant/research support from: Abbott Laboratories, Amgen Inc, AstraZeneca Pharmaceuticals LP, Bristol-Myers Squibb, F.HoffmannLa Roche Inc, Janssen Inc, Lilly Pharmaceuticals, Novartis Pharmaceuticals, Pfizer Pharmaceuticals, Sanofi-Aventis, UCB, Consultant for: Abbott Laboratories, AstraZeneca Pharma, Biotest, Bristol-Myers Squibb Company, Crescendo Bioscience, F Hoffmann-La Roche Inc, Genentech Inc, Janssen Inc, Lilly Pharmaceuticals,Merck, Pfizer Pharmaceuticals, UCB, Speakers bureau: Abbott Laboratories, AstraZeneca LP, Bristol-Myers Squibb Canada, F Hoffmann-La Roche Inc, Janssen Inc, Pfizer Pharmaceuticals, UCB,Amgen, D. Tin: None declared, C. Thorne Grant/research support from: AbbVie, Amgen, Celgene, CareBiodam, Lilly, Norvartis, Pfizer, Sanofi, UCB, Consultant for: AbbVie, Amgen, Celgene, Centocor, Genzyme, Hospira Janssen, Lilly, Medexus/Medac, Merck, Novartis, Pfizer, Sanofi, UCB, Speakers bureau: Medexus/MEdac, J. Pope Grant/research support from: Amgen, BMS, Pfizer, Roche, UCB, Consultant for: AbbVie, Actelion, Amgen, Bayer, BMS, Genzyme, Hospira, Lilly, Merck, Norvartis, Pfizer, Regeneron, Roche, Sandofi, UCB, V. Bykerk Shareholder of: Biogen (family), Consultant for: Abbvie, Pfizer, Genenech/Roche, Regeneron, BMS, UCB, Employee of: Biogen (family), C. Hitchon Grant/research support from: UCB DOI: 10.1136/annrheumdis-2017-eular.3328

\section{SAT0040 ASSESSING 5-YEAR RADIOGRAPHIC PROGRESSION IN RHEUMATOID ARTHRITIS PATIENTS WITH MODERATE DISEASE: FINDINGS FROM A UK MULTI-CENTRE PROSPECTIVE OBSERVATIONAL STUDY}

L. Carpenter ${ }^{1}$, S. Norton ${ }^{2}$, E. Nikiphorou ${ }^{3}$, K. Jayakumar ${ }^{4}$, D.F. McWilliams ${ }^{5}$, J. Dixey ${ }^{6}$, P. Kiely ${ }^{7}$, D.A. Walsh ${ }^{5}$, A. Young ${ }^{4}$ on behalf of ERAS and ERAN. ${ }^{1}$ Life and Medical Sciences, University of Hertfordshire; ${ }^{2}$ Psychology Department, Institute of Psychiatry; ${ }^{3}$ Department of Rheumatology, Whittington Hospital NHS Trust, London: ${ }^{4}$ Department of Rheumatology, St Albans City Hospital, St Albans; ${ }^{5}$ Arthritis UK Pain Centre, University of Nottingham, Nottingham; ${ }^{6}$ Department of Rheumatology, New Cross Hospital, Wolverhampton;

${ }^{7}$ Department of Rheumatology, St Georges University Hospitals NHS Foundation Trust, London, United Kingdom

Background: Early, intensive treatment to achieve remission, or at least low disease target (Treat-to-Target, T2T), is advocated to prevent and/or reduce structural joint damage and disability in early Rheumatoid Arthritis (RA). A recent study shows how patients with moderate disease exhibit similar rates of functional disability and orthopaedic surgical interventions to those patients with high disease ${ }^{1}$. To our knowledge, no study has looked at longitudinal observational data to investigate the progression of structural joint damage in these patient sub-groups.

Objectives: To investigate the long-term progression of radiographic joint damage in patients with sustained moderate disease activity.

Methods: Demographic, clinical, laboratory and radiographic data from the Early Rheumatoid Arthritis Study (ERAS) was available for 1,465 patients. Radiographic damage was scored using the modified Sharp/van der Heijde (SvdH) method. The original three variable 44 joint count Disease Activity Score (DAS-44) was used. Mean DAS-44 over the first 5 years was estimated for patients with at least two DAS-44 scores. Patients were stratified based on EULARs thresholds of low (<2.4), moderate (2.4-3.7) and high (>3.7) disease. Mixed-effects negative binomial regression modelled patients' radiographic progression over 5 years, whilst controlling for key confounders, including age at onset, sex, rheumatoid factor status and baseline functional disability.

Results: A total of 1,110 patients with 3,751 observations over the 5 year period (mean $=3.4$ observations per patient) were analysed. $396(36 \%), 363(33 \%)$ and $351(32 \%)$ patients were classified in the low, moderate and high DAS-44 groups respectively. The low group had lower SvdH scores at 1 year compared to the moderate group $(12.9$ vs. $19.2, p<0.001)$. Furthermore, the low group also experienced half the annual rate of change over the 5 years compared to the moderate group ( 3.6 vs. $7.4, p=0.002$ ). In contrast, the high group had similar $\mathrm{SvdH}$ scores at year 1 compared the moderate group (20.4 vs. $19.2, p=0.884$ ), but increased annual progression over the 5 years ( 10.0 vs. $7.4, p=0.010)$. Despite the increased annual progression rate, the difference in SvdH scores between the moderate and high groups remained non-significant at 5 years.

Conclusions: Sustained moderate disease over the first five years of RA indicates similar levels of radiographic progression compared to sustained high disease.

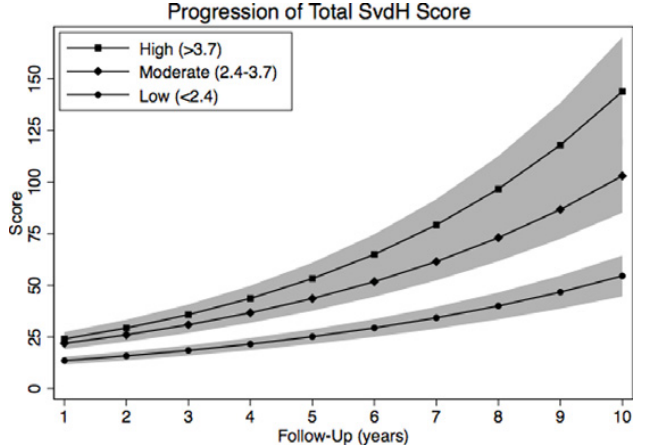

This study provides support on the importance of tight treatment control with early and aggressive therapy according to T2T principles. Preventing sustained moderate disease activity states can help reduce radiographic progression and consequently joint destruction, minimising the risk of disability in the long-term.

\section{erences:}

[1] Nikiphorou, E. et al. Association between rheumatoid arthritis disease activity, progression of functional limitation and long-term risk of orthopaedic surgery: combined analysis of two prospective cohorts supports EULAR treat to target DAS thresholds. Ann. Rheum. Dis. annrheumdis-2015-208669 (2016).

Disclosure of Interest: L. Carpenter Grant/research support from: NIHR Programme Grant, S. Norton: None declared, E. Nikiphorou: None declared, K. Jayakumar: None declared, D. McWilliams: None declared, J. Dixey: None declared, P. Kiely: None declared, D. Walsh: None declared, A. Young: None declared DOI: 10.1136/annrheumdis-2017-eular.3893

\section{SAT0041 EFFICACY OF ABATACEPT VERSUS ADALIMUMAB IN PATIENTS WITH SEROPOSITIVE, EROSIVE EARLY RA: ANALYSIS OF A RANDOMIZED CONTROLLED CLINICAL TRIAL (AMPLE)}

R. Fleischmann ${ }^{1}$, M. Weinblatt ${ }^{2}$, H. Ahmad ${ }^{3}$, M. Maldonado ${ }^{3}$, E. Alemao ${ }^{3}$, J. Ye ${ }^{3}, \mathrm{M}$. Schiff ${ }^{4} .{ }^{1}$ University of Texas Southwestern Medical Center, Dallas; ${ }^{2}$ Brigham and Women's Hospital, Boston; ${ }^{3}$ Bristol-Myers Squibb, Princeton; ${ }^{4}$ University of Colorado, Denver, United States

Background: Patients (pts) who are anti-citrullinated protein antibody (ACPA) positive tend to develop more severe erosive disease than ACPA-negative pts. The presence of seropositivity and erosions have been noted in EULAR treatment guidelines as poor prognostic factors to identify pts with RA who require early and aggressive clinical intervention. ${ }^{2}$ Since the disease in pts with seropositive, erosive early RA is mostly driven by immunological features, response to RA therapy may vary based on therapeutic mechanism of action (MOA).

Objectives: To investigate the efficacy of abatacept (ABA) vs adalimumab (ADA) in pts with seropositive, erosive early RA.

Methods: AMPLE (NCT00929864) ${ }^{3}$ was a 2-year, Phase Illb study in which biologic-naïve pts with RA were randomized 1:1 to either SC ABA 125 mg weekly or SC ADA $40 \mathrm{mg}$ biweekly, both with background MTX. This post hoc analysis of AMPLE compared clinical outcomes between treatment groups in a subpopulation of pts with specified baseline criteria: disease duration $\leq 6$ months, RF or ACPA seropositivity and $>1$ radiographic erosion. Disease activity and patient-reported outcomes were evaluated at Weeks 26, 52 and 104. Endpoints were compared between ABA and ADA groups using chi-square test for categorical variables, analysis of covariance model (ANCOVA) controlling for baseline covariates and DAS28 (CRP) stratification for continuous variables.

Results: Of 318 and 328 pts in the ABA and ADA groups, respectively, 38 and 45 pts had all specified baseline characteristics (Cohort 1) and 280 and 283 pts had an absence of at least 1 of the specified characteristics (Cohort 2). Overall, the baseline characteristics, including anti-cyclic citrullinated peptide titres, were well balanced between the groups, with the exception of weight. For Cohort 1, adjusted mean change $(95 \% \mathrm{Cl})$ from baseline DAS28 (CRP) with ABA vs ADA was $-2.18(-2.61,-1.75)$ vs $-1.56(-2.01,-1.11)$ at Week 26, $-2.58(-2.99$, $-2.17)$ vs $-1.68(-2.10,-1.25)$ at Week 52 and $-2.50(-2.97,-2.03)$ vs -2.0 $(-2.49,-1.50)$ at Week 104. Similar trends of increased efficacy with ABA vs ADA were observed for changes from baseline CDAI, SDAI, HAQ-DI, pain and fatigue; no differences in radiographic progression were observed. For Cohort 2, no differences in clinical outcomes between ABA and ADA groups were observed. Given the differences in baseline weight between ABA and ADA groups in Cohort 1 , sensitivity analyses that excluded pts $>100 \mathrm{~kg}$ and adjusted for baseline weight were performed and demonstrated minimal effect of weight on treatment efficacy. Conclusions: This post hoc analysis seems to indicate a trend of increased efficacy for abatacept in pts with seropositive, erosive early RA compared with the TNF inhibitor adalimumab. Given the small sample size, additional pre-specified randomized studies are needed to compare the benefit of biologic DMARDs with different MOAs in pts with early, rapidly progressing RA.

References:

[1] Combe B, et al. Ann Rheum Dis 2016 Dec 15. doi: 10.1136/annrheumdis2016-210602. 